\title{
Data beträffaude frekvensen af jotniska saudstensblock i de mellanbaltiska trakternas istidsaflagringar
}

\section{H. Hausen}

To cite this article: H. Hausen (1912) Data beträffaude frekvensen af jotniska saudstensblock i de mellanbaltiska trakternas istidsaflagringar, Geologiska Föreningen i Stockholm Förhandlingar, 34:5, 495-499, DOI: 10.1080/11035891209446954

To link to this article: http://dx.doi.org/10.1080/11035891209446954

曲 Published online: 06 Jan 2010.

Submit your article to this journal $₫$

Џll Article views: 7

Q View related articles ¿ 
GEOL. FöREN. FÖRHANDL. Bd 34. Häft. 5. Maj 1912. 495)

\section{Data beträffaude frekrensen af jotniska sandstensblock $i$ de mellambaltiska trakternas istidsaflagringar.}

Af

H. Hausen.

Ehuru några närmare undersölningar angảende utbredningen af jotniska sandstensblock i trakterna kring norra Östersjön ännu ej blifvit verkställda, föreligga likvall iakttagelser från så pass vidstrückta områden, att man på grund af blockens frekvens är berättigad till vissa slutsatser. Jämte det jag nedan $\mathrm{i}$ korthet berör dessa, bifogar jag en liten öfrersiktskarta, fig. 1 , visande utbredningen af sandstensblocken, äfvensom hvar anrikningen af dessa block är störst.

Tidigare uppgifter angående frekvensen af jotniska sandstensblock i Mellanbaltikum hürstamma från C. WISraN, ${ }^{1}$ som utfört ett antal stenräkningar i Upland, früimst med afseende a förekomsten af silurkalkstensblock. Ofriga data föreligga, så vidt jag vet, icke frản denna del af Sverige. På finsk sida är det först under senaste somrar några närmare uppgifter erhållits, $\mathbf{i}$ det att författaren utfört ett antal stenräkningar, dels på Alland, 2 dels i olika delar af SW:a Finlands fastland. Här nedan må till en början meddelas några procenttal öfver mängden af sandstensblock längs en sträcka från Upsala öfver Alland till Borgå:

1 C. Wrarax: Stadien über das nordbaltische Silurgebiet. Ball. of the Geol. Inst. of Upsala. Vol. VI. 1902-03.

? H. HAUSEN: Stenräkningar på Åland. G. F. F. 33, 1911. 
8

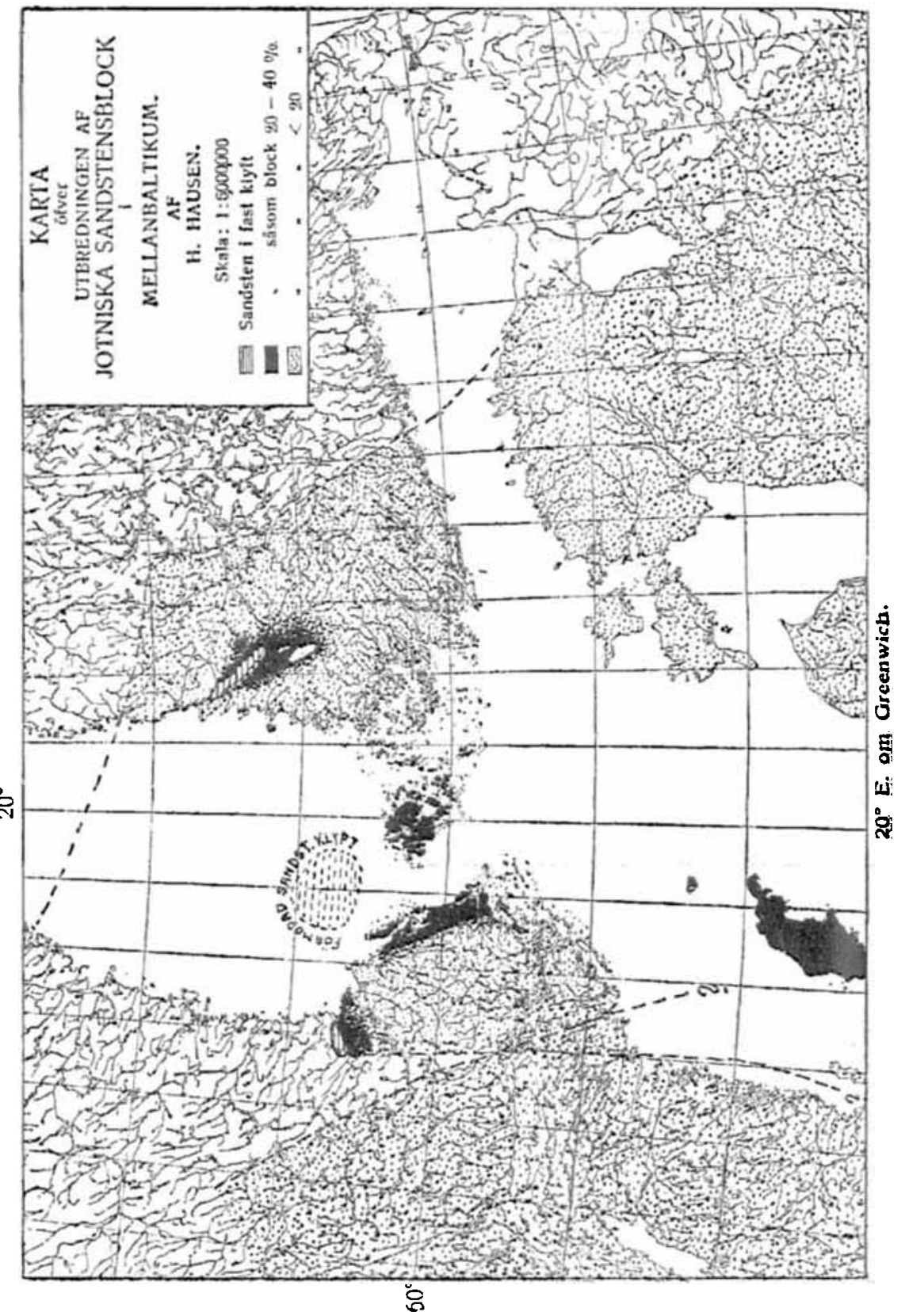


Upsalaåsen . . . . . . . . . . . . . . . . $14 \%$ Björkö, Marum (morïn) . . . . . . . . . . 25-34\% Alland (morian, rullstensgrus) . . . . . . . . . . . . . . . . . . . . ఏbo (rullstensgrus) . . . . . . . . . . . . 2-4\% Karis (rullstensgrus) . . . . . . . . . 3-4\% Hoplax, H:fors (morän) . . . . . . . $1 \%$ Borgå (rullstensgrus) . . . . . . . . . . $0 \%$

Hürtill må ännu fogas följande nppgifter. På det finska fastlandet har jag anträffat jotnisk sandsten nordligast mellan Ruovesi och Virdois, ostligast vid Tammerfors, Hyvinge och Kervo. Uti grustagen utmed Hyvinge-Hangö-banan, hvilka af mig granskats, üro sandstensblocken $i$ allmünbet af samma frekvens som vid Karis. I skärningar utmed Åbo -Toijala-banan uppträda sandstensblocken, enligt hvad jag konstaterade, vida rikligare.

Af de olika sandstensvarieteterna ür den finkorniga röda, rödbruna eller violetta den ojämförligt allmännaste, åtminstone inom Finland. Därnäst kommer i mängd en grofliornig, stundom konglomeratartad arkos med bruna fältspat- och mjölkhvita kvartskorn. Jämförelsevis sällsynta äro ljusa afarter eller helt hvita, kvartsitiska sandstenar. Märkligt är, att, medan den finkorniga röda sandstenen är spridd ofver hela det på kartan angifna området (i Finland), den grofkorniga når sin östra gräns redan i trakten af Ingå (förf:s observation). Den östra spridningsgränsen för jotniska sandstensblock angifver alltså endast den röda finkorniga varietetens extrema utbredning. Att denna varietet är den allmännaste som block i SW:a Finland, har för öfrigt redan påpekats af Griliva. ${ }^{1}$ Märkligt nog förekommer den ej $i$ de hittills kända sandstensklyfterna vid Kumo älf och Pyhäjärvi annat ün mycket sparsamt. $D_{\AA}$ den emellertid i närheten (särskildt i Luvia) uppträder synnerligen rikligt i moränen,

1 HJ. Grutrig: Zur Geologie der cambrischen Arkosenablagerung des westlichen Finnlands. Zeitschr. d. Deutsch. Geol. Ges. 1857, sid. 770. 
förmodar Gyluiva, att anstående klyft döljer sig dürstädes under kvartärtäcket.

På Åland är den röda finkorniga varieteten afgjordt i ma. joriteten; därnäst kommer den konglomeratartade.

I Östersjöprovinserna har fürf. något füljt utbredningen af de jotniska sandstensblocken och funnit, att deras östra gräns framgår ungefär öfver Peipus I allmänhet är blockens upp. trädande rätt sparsamt, vtom närmast Östersjön, där en stark anrikning gör sig gällande (Dagö, W:a Kurland).

$\mathrm{På} \mathrm{Gotland} \mathrm{har} \mathrm{H.} \mathrm{Hedsrnöy}{ }^{1}$ företagit ett antal stenräkningar och funnit, att jotniska (skambriskas) sandstens. block i morän vid Visby uppträda med c:a $10-44 \%$

Med ledning af ofvan anförda data återstâr att utreda ursprungsorterna för allt det blockmaterial, som sålunda blifvit spridt öfver ifrågavarande trakter.

Till en början uppställer sig frågan, huruvida Dalarnes stora sandstensformation kan anses hafva influerat på frekven. sen $i$ dessa trakter. Enligt de undersökningar, som utförts af AmnofF 2 öfver Elfdalsporfyrernas utbredning, framgár dessas östra gräns $\mathrm{i}$ en mot $\mathrm{NE}$ svagare konvex båge ungefär i NW-SE:lig riktning öfver Stockholm. Ostgränsen för Dalarnes sandstensblock ginge då tydligen efter en med denna parallell, i någon mån västligare dragen linje, och har dess läge antydts på medföljande lilla karta. Häraf synes, att blockfrekvensen i Upland, SW:a Finland och åtminstone i norra Östersjöprovinserna icke står $i$ något beroende af Dalasandstenen (sannolikt i mycket ringa grad på Gotland). De i mellanbaltikum kïinda sandstensklyfterna äro ju Gefle- och Satakuntaområdena. Det förra har förorsakat en rätt stor frekvens i mellersta Upland (Upsalaåsen $14 \%$ ), det senare har, jämte den af GrLlisa förmodade, men icke synliga sand-

1 H. IIEDSTröy: Stadier öfver bergarter från morän vid visby. G. F. F. 16 (1891): $26 \mathrm{~S}$.

2 G. Amnoff: Om Elfdalsporfyrernas utbredning som block i östra Srerige. G. F. F. 25 (1905): 421 . 
stensklyften i närheten, lämnat det hufvudsakliga materialet till blockmăngden å SW-Finlands fastland, äfvensom i någon mân till den $\mathrm{i}$ Östersjöprorinserna. Däremot är det uppenbart, att den starka anrikningen på Åland och i ostligaste Upland icke kan stå i något beroende af ofvannämnda sandstensklyfter, utan att bloclivikcdomen härstädes förshrifver sig frin hafsbottnen mellan Alland och Gäfle. Att denna submarina klyft hrarken kan ligga nordligare eller ostligare, framgår af sandstensblockens sparsamma förekomst i Ảbotrakten. Landisens rörelseriktning har ju ảtminstone under Salpausselkä-stadiet ${ }^{1}$ i östra delen af Bottenhafret varit c:a NW-SE:lig, hvarför man skulle vänta sig en vida större rikedom på sandstensblock i Ảbotrakten, om den förmodade sandstensklyften hade ett frîn det förstnämnda afvikande lüge. Den starka anrikningen $i$ västligaste Kurland talar äfven för en transport från trakten af Ålands haf. ${ }^{2}$

\footnotetext{
1 J. J. SedenHowy: Isrörelsen i Fennoskandia. Atlas öfrer Finland 1910.

2 Ied hänsyn till frekrensen. pi Gotland kunde man vïnta sig att finna

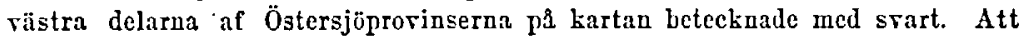
så icke är förhållandet, beror därpå, att stenräkningar i detta syfte inom ifrågavarande trakt ej företagits.
} 